\title{
Annonaceous acetogenin mimic AA005 induces cancer cell death via apoptosis inducing factor through a caspase-3-independent mechanism
}

\author{
Bing Han ${ }^{1}$, Tong-Dan Wang ${ }^{1}$, Shao-Ming Shen ${ }^{1}$, Yun Yu' ${ }^{1}$, Chan Mao ${ }^{2}$, Zhu-Jun Yao ${ }^{2,3}$ and Li-Shun Wang ${ }^{1,3^{*}}$
}

\begin{abstract}
Background: Annonaceous acetogenins are a family of natural products with antitumor activities. Annonaceous acetogenin mimic AA005 reportedly inhibits mammalian mitochondrial NADH-ubiquinone reductase (Complex I) and induces gastric cancer cell death. However, the mechanisms underlying its cell-death-inducing activity are unclear.
\end{abstract}

Methods: We used SW620 colorectal adenocarcinoma cells to study AA005 cytotoxic activity. Cell deaths were determined by Trypan blue assay and flow cytometry, and related proteins were characterized by western blot. Immunofluorescence and subcellular fractionation were used to evaluate AIF nuclear translocation. Reactive oxygen species were assessed by using redox-sensitive dye DCFDA.

Results: AA005 induces a unique type of cell death in colorectal adenocarcinoma cells, characterized by lack of caspase-3 activation or apoptotic body formation, sensitivity to poly (ADP-ribose) polymerase inhibitor Olaparib (AZD2281) but not pan-caspase inhibitor Z-VAD.fmk, and dependence on apoptosis-inducing factor (AIF). AA005 treatment also reduced expression of mitochondrial Complex I components, and leads to accumulation of intracellular reactive oxygen species (ROS) at the early stage. Blocking ROS formation significantly suppresses AA005-induced cell death in SW620 cells. Moreover, blocking activation of RIP-1 by necroptosis inhibitor necrotatin-1 inhibits AIF translocation and partially suppresses AA005-induced cell death in SW620 cells demonstrating that RIP-1 protein may be essential for cell death.

Conclusions: AA005 may trigger the cell death via mediated by AlF through caspase-3 independent pathway. Our work provided new mechanisms for AA005-induced cancer cell death and novel clues for cancer treatment via AIF dependent cell death.

Keywords: Annonaceous acetogenins, Cancer, AlF, ROS, RIP-1

\section{Background}

Biochemical qualities of the Annonaceae (custard-apple) family are not completely known due to its large size (130 genera and 2300 species) [1]. Many Annonaceae species have been used in folk medicine and as insecticides [2]. Products from the Annonaceae family, collectively called annonaceous acetogenins (AAs), are very

\footnotetext{
* Correspondence: jywangls@shsmu.edu.cn

${ }^{1}$ Center for Molecular Medicine, Ruijin Hospital, Shanghai Jiao Tong

University School of Medicine, Shanghai 200025, China

${ }^{3}$ Shanghai Universities E-Institute for Chemical Biology, Shanghai 200025, China

Full list of author information is available at the end of the article
}

potent inhibitors of mammalian mitochondria NADHubiquinone reductase (Complex I) [3]. To date, over 400 members of this compound family have been found, most of which have been proven to exhibit high cytotoxic and antitumor activities [1]. Over the past few years, we have successfully developed a series of AA mimetics. More interestingly, we found that some of these analogues have significant selectivity between human cancer cells and normal cells [4]. AA005 shows the best inhibitory effect against several human cancer cell lines [5], although its exact mechanisms are largely unknown.

Mitochondria are the central relay station for apoptotic signal transduction. In response to apoptotic stimulus, 
permeabilized mitochondria release cytochrome $\mathrm{c}$ into the cytoplasm, where cytochrome c forms an apoptosome with Apaf- 1 and caspase- 9 and triggers the caspase cascade. The most important caspase in this cascade is caspase-3, which is cleaved and activated to transduce the apoptotic signal [6,7]. Mitochondria can also release apoptosisinducing factor (AIF) to initiate caspase-independent cell death [8,9]. The mitochondrial flavoprotein AIF is a caspase-independent cell-death-inducing factor [10]. During apoptotic signaling without caspase- 3 activation, AIF is released from the mitochondria when the mitochondrial membrane is permeabilized, then translocates to the nucleus where it induces cell death by triggering chromatin condensation and large-scale DNA fragmentation into $\sim 50$-kilobase strands with the help of other proteins such as Endo G (C. elegans), CypA (mice) or FEN-1 [10-17]. Here we report that AA005 may trigger caspase-3independent cell death, mediated by AIF. Our work may provide novel therapeutic clues for treating cancers via a non-canonical apoptotic pathway.

\section{Methods}

\section{Cell culture and treatments}

Human colorectal adenocarcinoma cell line SW620, breast cancer cell line BT-549, and U937 acute myelomonocytic leukemic cell line came from the Cell Bank of Shanghai Institutes for Biological Sciences (Shanghai, China); acute promyelocytic leukemia (APL) cell line NB4 were kindly provided by Dr. M. Lanotte in France [18]. These cells were cultured in RPMI-1640 medium (Sigma-Aldrich, St Louis, MO) supplemented with $10 \%$ heat-inactivated fetal calf serum (FCS; HyClone, Logan, $\mathrm{UT}$ ) in a $5 \% \mathrm{CO}_{2}$ humidified atmosphere at $37^{\circ} \mathrm{C}$. For experiments, cells were seeded at $2-5 \times 10^{5}$ cells $/ \mathrm{ml}$ and incubated with the indicated concentrations of AA mimic AA005 (kindly provided by Institute of Chemical Biology and Drug Innovation, School of Chemistry and Chemical Engineering, Nanjing University, Nanjing, China), MNNG (Sigma-Aldrich), and camptothecin (kindly provided by National Cancer Institute Anticancer Drug Screen standard agent database, Bethesda, MD) with or without caspase inhibitor Z-VAD.fmk (Sigma-Aldrich). AA mimic AA005 were dissolved in $75 \%$ ethanol as a $1 \mathrm{mM}$ stock solution and was kept at $-80^{\circ} \mathrm{C}$. MNNG (100 mM) was freshly prepared in dimethylsulfoxide (DMSO) and diluted in culture media to $0.5 \mathrm{mM}$. After treatment for $15 \mathrm{~min}$, cells were washed and returned to the normal growth medium. camptothecin was dissolved in double-distilled water as a $1 \mathrm{mM}$ stock solution. ZVAD.fmk was dissolved in DMSO before use.

\section{Trypan blue assay}

After treatments cells were harvested, resuspended in cell growth medium, and diluted 1:1 with $0.4 \%$ trypan blue stain (Sigma-Aldrich). Stained and unstained cells were counted using a hemocytometer.

\section{TUNEL assay}

Cells were seeded in 6-well plates 1 day prior to treatments. Fragmented DNA was assessed using terminal deoxynucleotidyl transferase (TdT)-dUTP nick endlabeling (TUNEL) kit (Roche) according to the manufacturer's protocol.

\section{DNA gel electrophoresis}

Appropriate $10^{6}$ cells were harvested, and pellets were suspended in lysis buffer $(0.1 \mathrm{M} \mathrm{NaCl}, 50 \mathrm{mM}$ Tris- $\mathrm{HCl}$, pH 7.5, 10 mM EDTA (ethylenedia-minetetraacetic acid), $0.5 \%$ sodium dodecyl sulfate [SDS], $500 \mu \mathrm{g} / \mathrm{ml}$ protease $\mathrm{K})$. After a 30 minutes, incubation on ice, samples were centrifuged at 14,000 g for 30 minutes, and cellular DNA was extracted. The samples were electrophoresed in $2 \%$ agarose gel at $100 \mathrm{~V}$ in $40 \mathrm{mM}$ Tris-acetate buffer $(\mathrm{pH} 7.4)$ and visualized by ethidium bromide staining.

\section{Flow cytometric assays for Annexin-V}

Briefly, about $10^{6}$ cells were rinsed with phosphatebuffered saline (PBS), and Annexin-V assay was performed on a flow cytometry (Beckman Coulter) according to instructions provided by the ApoAlertAnnexin-V kit (Clontech, PaloAlto, CA) as well as stained with $50 \mu \mathrm{g} / \mathrm{ml}$ propidium iodide (PI; Sigma).

\section{RNA interference and transfection}

For siRNA in SW620 cells, the following oligonucleotides were inserted into RNAi-Ready pSIREN-RetroQ vector (Clontech, Palo Alto, CA): 5'-TAGCGGTCGCCGAA ATGTT-3' (A3) and 5'-CTGGTATCCGATCAGAGAG-3' (A5) for AIF, and 5' -ACTACCGTTGTTATAGGTG-3' for scrambled negative control. Retrovirus with these shRNA produced in $293 \mathrm{~T}$ cells were used to infect SW620 cells. Stable retroviral transduction was achieved by infection for $48 \mathrm{~h}$, after which selection with puromycin was initiated. Selection was stopped as soon as the non-infected control cell died off. Media were then replaced with normal growing medium.

\section{Western blots}

The protein lysates were mixed with equal volume of Laemmli buffer (62.5 mM Tris- $\mathrm{HCl}, \mathrm{pH} 6.8,2 \%$ sodium dodecyl sulfate, $50 \mathrm{mM}$ Dithiothreitol, 10\% glycerol, $0.01 \%$ bromophenol blue), boiled for $3 \mathrm{~min}$ at $100^{\circ} \mathrm{C}$ and then resolved by sodium dodecyl sulfate-polyacrylamide gel electrophoresis on a $10 \%-12 \%$ gel using a mini gel apparatus (Bio-Rad, Hercules, CA). Subsequently, the proteins were electrophoretically transferred to a nitrocellulose membrane (Bio-Rad). The membranes were blocked with $5 \%$ nonfat dry milk solution in Tris- 
buffered saline with $0.1 \%$ Tween-20 for $1 \mathrm{~h}$ at room temperature and then incubated in primary antibody dissolved in block solution at $4^{\circ} \mathrm{C}$ overnight. The proteins were probed by antibodies against AIF (Cell Signaling, Beverly, MA), with mouse anti- $\beta$-actin mAb (Merck, Darmstadt, Germany) to confirm equal loading. After washing, the blots were incubated with horseradish peroxidase-conjugated secondary antibody (Dako Cytomation, Glostrup, Denmark) corresponding to the primary antibody in blocking buffer for $1 \mathrm{~h}$ at room temperature, and detections were performed by Super Signal West Pico Chemiluminescent Substrate kit (Pierce, Rockford, IL) according to the manufacture's instructions.

\section{Immunofluorescence}

Colorectal adenocarcinoma cells were crawled onto cover slides, fixed with $4 \%$ paraformaldehyde and permeabilized with $0.3 \%$ Triton X-100 for 10 min. Slides were blocked with $1 \%$ bovine serum albumin and incubated with rabbit anti-AIF monoclonal antibody (1:100) overnight at $4^{\circ} \mathrm{C}$. After washing in PBS, the cells were stained with secondary antibodies (FITC-conjugated bovine antirabbit; 1:200; Santa Cruz Biotech) and incubated for $1 \mathrm{~h}$ in room temperature, followed by nuclear counterstaining with DAPI. Fluorescence signals were detected on a Olympus BX-51 fluorescence microscope (Tokyo, Japan).

\section{Detection of ROS by flow cytometry}

Cells were washed with phosphate-buffered saline (PBS), re-suspended in pre-warmed $\mathrm{PBS}\left(37^{\circ} \mathrm{C}\right)$, and incubated with $10 \mathrm{mM}$ 5-(and 6)-chloromethyl-2', $7^{\prime}$-dichlorodihydrofluorescein diacetate, acetyl ester (C-6827, CM-H2DCFDA, Invitrogen, Carlsbad, CA, USA) for $30 \mathrm{~min}$ at $37^{\circ} \mathrm{C}$. Cells were then washed with PBS twice and scraped into $0.3 \mathrm{ml}$ of ice-cold PBS. CM-H2-DCFDA fluorescence

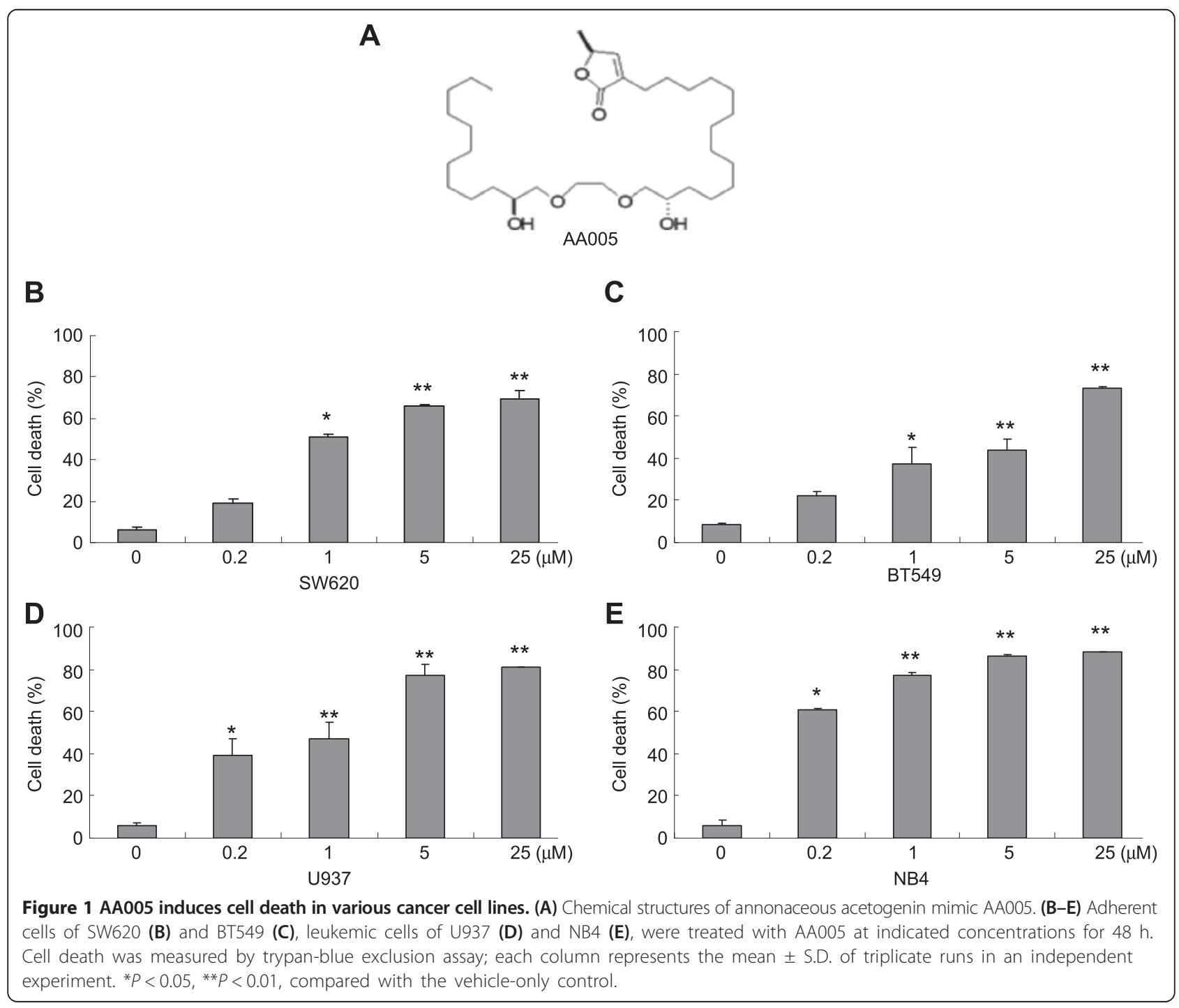




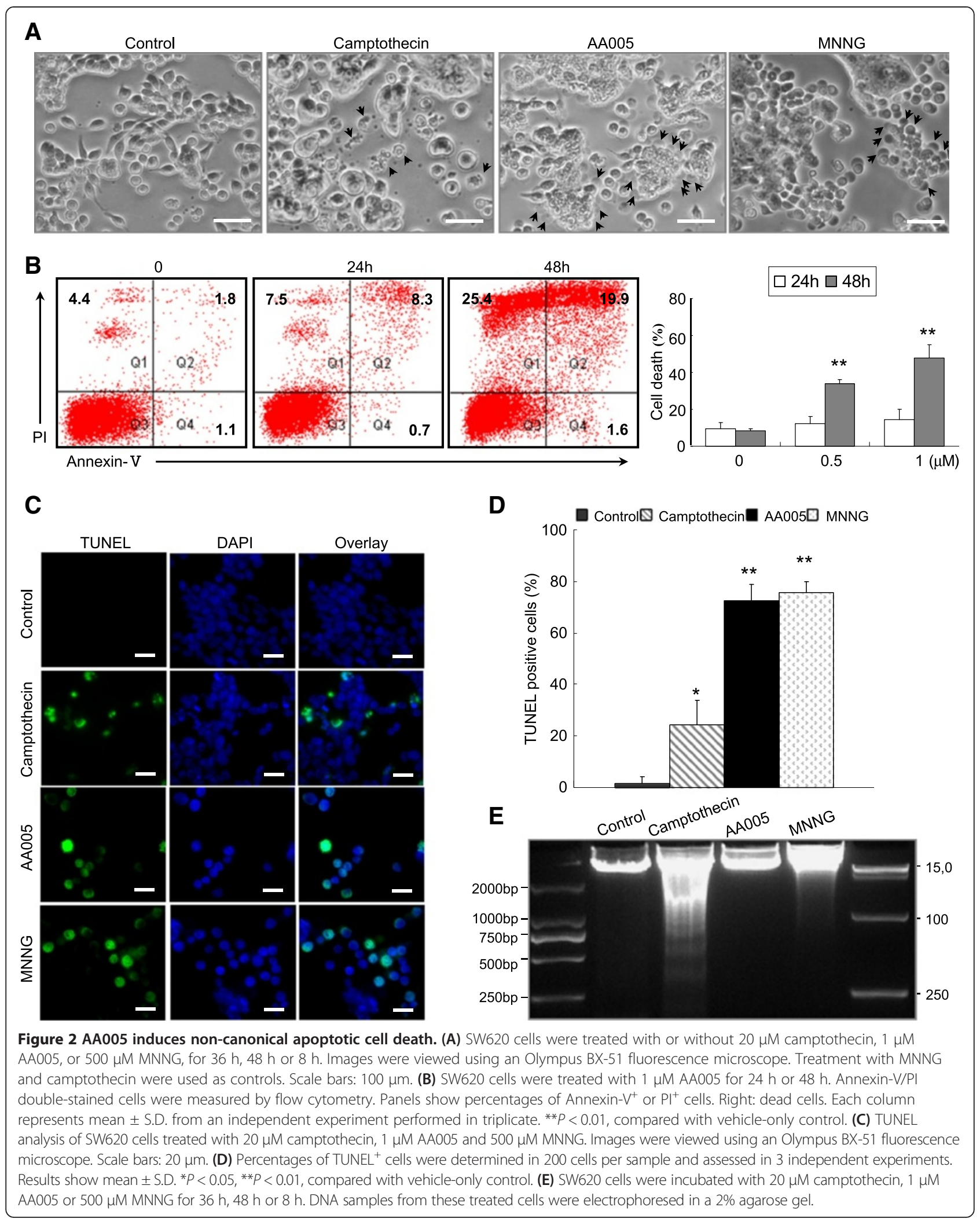


was determined by measuring 10,000 events per sample following excitation with a 488-nm wavelength laser and reading through a 530/30 filter (FACSCalibur, BD Bioscience, San Jose, CA, USA).

\section{Statistical analysis}

Each experiment was done independently at least 3 times with similar results. Results are expressed as mean \pm S.D. Significant differences were assessed with the Student's $t$ test (2-tailed). $P<0.05$ was considered to be significant.

\section{Results}

\section{AA005 induces cell death in various cancer cell lines}

To evaluate the potential cytotoxicity of AA mimic AA005 (Figure 1A) [19], we administered AA005 to colorectal adenocarcinoma cell line SW620, breast cancer cell line BT-549, acute promyelocytic leukemia cell line NB4, and acute myelomonocytic leukemic cell line U937, followed by cell viability analysis with trypan-blue exclusion assays.
Percentages of dead cells were $19.01 \pm 2.10 \%, 50.79 \pm 1.81 \%$, $66.20 \pm 0.80 \%$ and $69.55 \pm 3.68 \%$ respectively, when SW620 cells were treated with $0.2 \mu \mathrm{M}, 1 \mu \mathrm{M}, 5 \mu \mathrm{M}$ and $25 \mu \mathrm{M}$ AA005 for $48 \mathrm{~h}$ (Figure 1B). Similar results were obtained in other cell lines (Figure 1C, D, E). These results showed that the cell-death inducing activity of AA005 was general and dose-dependent.

\section{AA005 induces non-canonical apoptosis}

To investigate the biochemical and morphological changes during the process of AA005-induced cell death, SW620 cells were treated with AA005, N-methyl-N'-nitro-N-nitrosoguanidine (MNNG) [20], and camptothecin [21]. MNNG and camptothecin were used as controls for caspaseindependent and caspase-dependent cell death, respectively. AA005-induced cell death was clearly different from camptothecin-induced cell death, which was characterized by membrane shrinking, nuclear condensation, and disintegration of the dying cell into apoptotic bodies.

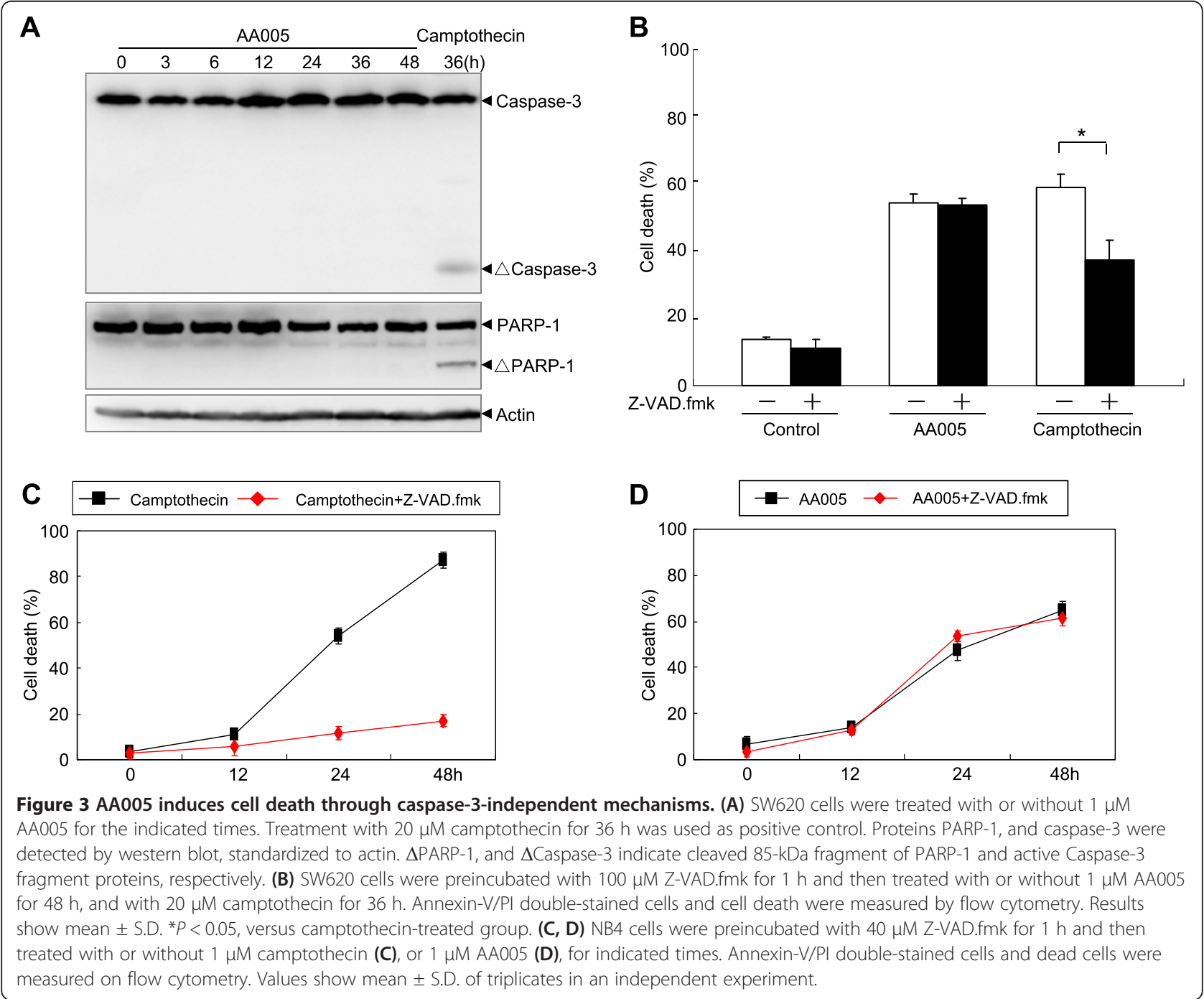


However, AA005-induced cell death is similar to MNNGinduced cell death during which massive cell death was triggered instantly at a certain time point, followed by the formation of cell membranes rupture, dissolution of organized structures and semi-circular shadows emerged around the dying cells (Figure 2A). Annexin-V/PI double stain-based flow cytometry analysis is the most sensitive and specific test for determining apoptotic cells, which are classified as Annexin- $\mathrm{V}^{+} / \mathrm{PI}^{-}$cells [22]. Although nearly 50\% of cells died at $48 \mathrm{~h}$ of AA005 treatment, no obvious Annexin- $\mathrm{V}^{+} / \mathrm{PI}^{-}$cells were detected throughout this process
(Figure 2B), indicating that AA005-induced cell death is not classical apoptosis. Furthermore, TUNEL analysis [23] of AA005-, camptothecin- and MNNG-treated SW620 cells are shown in Figure 2C. Although all three agents induced TUNEL ${ }^{+}$cells, AA005 and MNNG showed stronger effects than camptothecin (Figure 2C, D). However, DNA fragmentation analysis indicated that camptothecin but not AA005 or MNNG induced apoptosisspecific DNA-ladders (Figure 2E). These results indicate that AA005 induced non-canonical apoptotic cell death in SW620 cells.

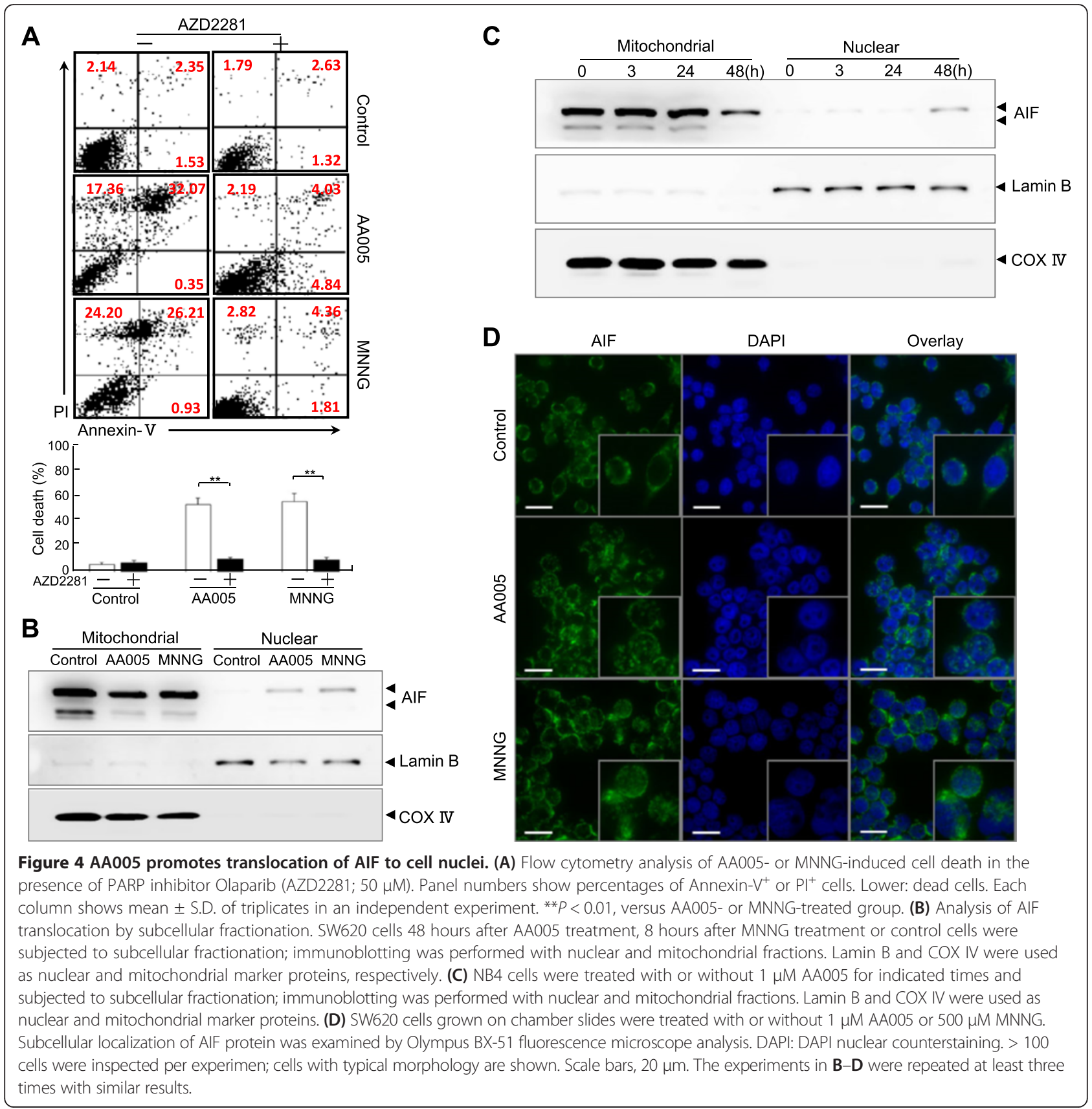




\section{AA005 induces cell death through a caspase-3 independent pathway}

To elucidate the mechanisms of AA005-induced cell death, we analyzed the involvement of caspase-3, an important executing caspase of apoptosis. Camptothecin treatment was used as a positive control. AA005 treatment failed to trigger cleavage of caspase- 3 and its substrate PARP-1, even when cell death was as high as 55\% (Figure 3A). Additionally, Z-VAD.fmk, a broadspectrum caspase inhibitor, greatly blocked camptothecininduced cell death, but showed no effect on AA005induced cell death (Figure $3 \mathrm{~B}$ ). To further investigate whether caspase- 3 played a role in AA005-induced cell death, we also tested caspase-3 activation in NB4 cells. Similarly, Z-VAD.fmk blocked most cell death triggered by camptothecin (Figure $3 \mathrm{C}$ ), but had no effect on the cell death induced by AA005 in NB4 cells (Figure 3D). Taken together, these results suggested that AA005 induced cell death through caspase-3 independent mechanisms.
AIF potentially contributes to AA005-induced cell death Our data showed that AA005-induced cancer cell death left morphology similar to that of MNNG-treated cells. Reportedly, MNNG-mediated cell death was AIF-mediated and PARP-1 dependent, resulting in a caspase-independent type of apoptosis, called parthanatos [20,24,25]. Interestingly, the mitochondrial flavoprotein AIF is well known as a caspase-independent apoptosis inducer [10]. For this reason, we speculated whether AIF played a role in AA005-induced cell death. We found that inhibition of PARP by Olaparib (AZD2281) [26] in SW620 cells completely blocked AA005 or MNNG-induced toxicity (Figure 4A). Under physiological conditions, AIF resides in the inter-membrane space of mitochondria and plays an essential role in maintaining mitochondrial function $[27,28]$. When it is released from mitochondria and translocates to the nucleus, it induces chromatin condensation and large-scale DNA cleavage in response to death stimuli [29]. We used immunofluorescence assay and subcellular fractionation to evaluate AIF

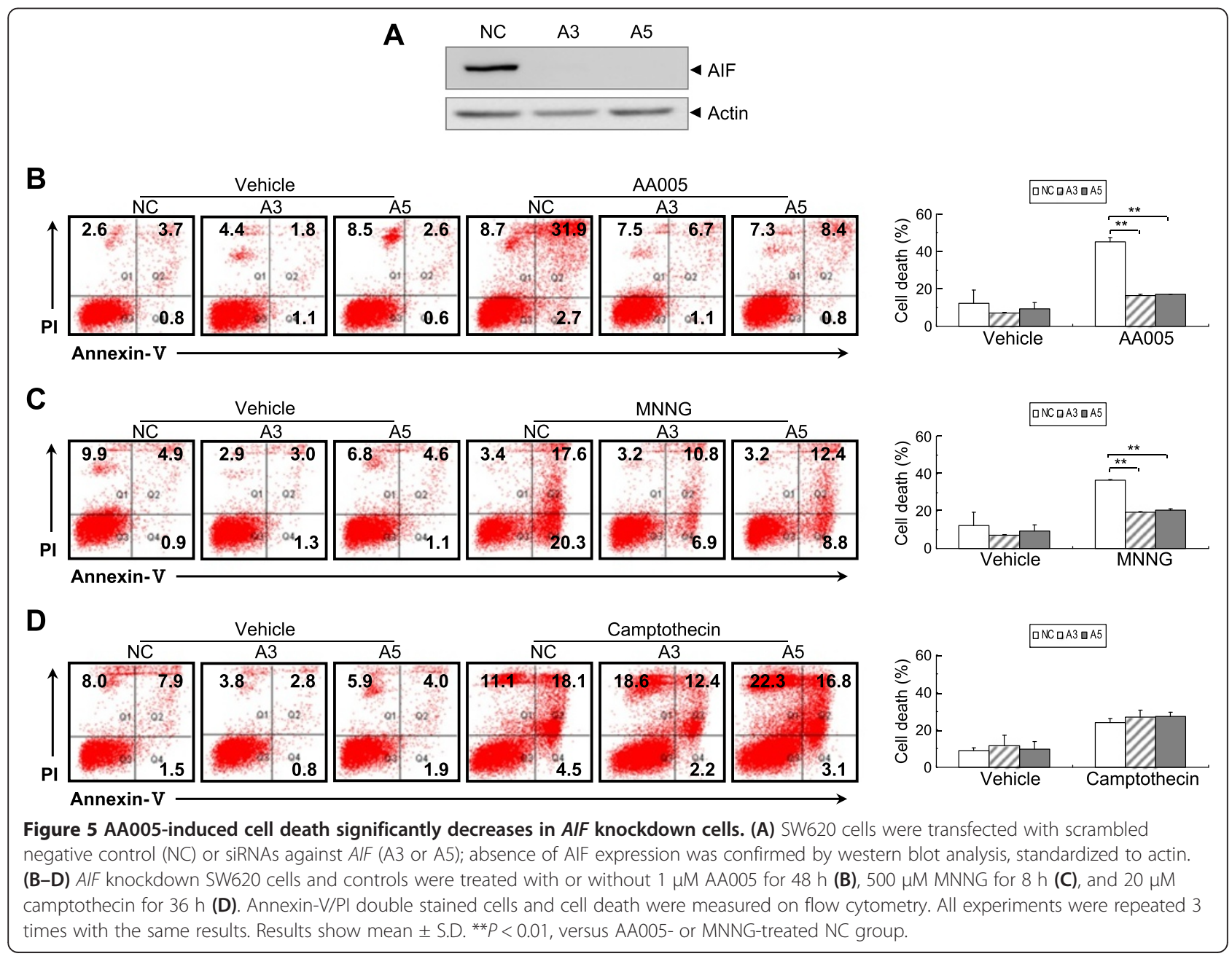


nuclear translocation. Nuclear translocation of AIF was readily observed by treatment with AA005 or the positive control MNNG in SW620 cells (Figure 4B), and similar findings in NB4 cells (Figure 4C). Immunofluorescence assays also showed AIF translocation into the nucleus after treatment with AA005 or MNNG (Figure 4D). Together, these results indicated that AA005 promotes AIF nuclear translocation.

To assess involvement of AIF, SW620 cells were transfected with retrovirus harboring $\mathrm{NC}$ or siRNAs against AIF (designated as A3 and A5; Figure 5A). Absence of AIF expression was confirmed by western blot analysis (Figure 5A). Furthermore, AIF knockdown almost completely blocked the cell death induced by AA005 (Figure 5B). We also confirmed that AIF knockdown inhibited the cell death induced by MNNG, the action of which is reportedly mediated by AIF (Figure 5C) [20], but had no effect on camptothecin-induced cell death, which is caspase-dependent (Figure 5D). Together, these results indicate that AA005 promote AIF nuclear translocation and trigger AIF-dependent cell death.

\section{ROS mediates AA005-induced cell death of SW620 cells}

Because release of AIF from the mitochondria and translocation to the nucleus occurred too late during AA005- induced cell death, the intrinsic cell death signaling at the early stage initiated by AA005 should be further investigated. Evidence from other studies suggests that AAs are potent inhibitors of mitochondrial NADHubiquinone reductase (Complex I) [3]. Based on this clue, we tested protein levels of Complex I subunits during AA005-induced cell death. Protein levels of Complex I subunits NDUFS1 and NDUFA10 decreased significantly after AA005 treatment (Figure 6A). Increased ROS concentrations caused by depletion of mitochondrial proteins led to activation of cell death signaling [30]. As we had shown AA005 treatment to decrease mitochondrial Complex I subunits, we next investigated ROS production during AA005-induced cell death. To address whether oxidative stress contributes to responses to AA005, SW620 cells were treated with AA 005 at $1 \mu \mathrm{M}$ for $1 \mathrm{~h}, 4 \mathrm{~h}$ or $12 \mathrm{~h}$, followed by incubation with fluorophore dichlorodihydrofluorescein diacetate (DCFDA), a dye to monitor intracellular ROS, for $30 \mathrm{~min}$. As expected, intracellular concentrations of ROS were significantly increased immediately after AA005 treatment and ROS levels maintained high from $1 \mathrm{~h}$ to $12 \mathrm{~h}$ (Figure 6B, C). Importantly, elevated ROS levels were necessary to mediate AA005-induced cell death, in that $\mathrm{N}$-acetyl-L-cysteine (NAC), an efficient

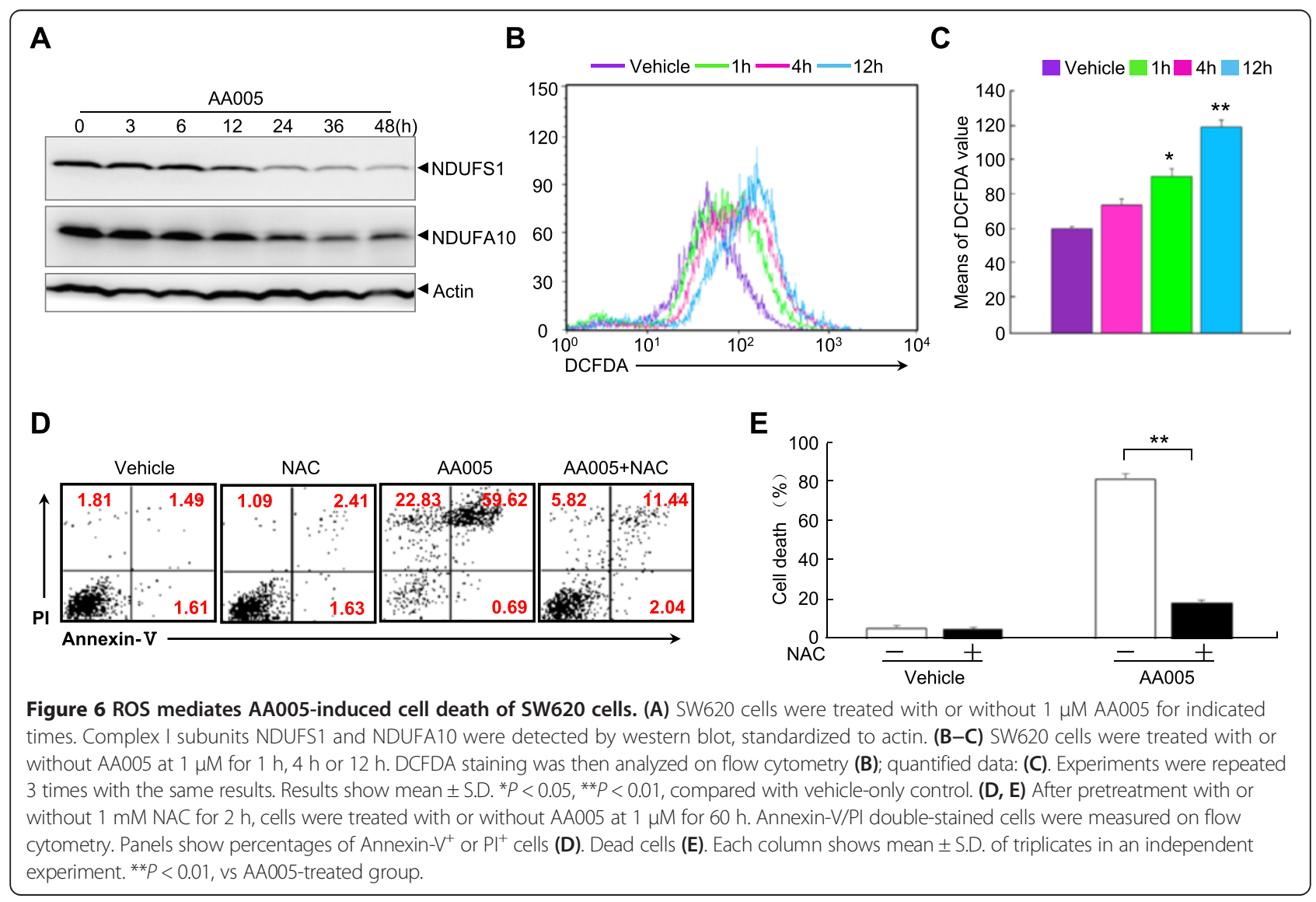


antioxidant, largely suppressed the number of dead cells (Figure 6D, E).

\section{RIP1 is required for AA005-induced cell death}

In our study, we showed that a previously unknown caspase-independent-AIF-dependent cell death was induced by AA005, and mediated through ROS. However, the underlying mechanisms remain unclear. The present study reported that the receptor interacting protein
(RIP)-1, a critical mediator of necroptosis, could modulate oxidative stress in AIF-dependent cell death [31,32]. To better understand the mechanisms, we examined the expressional level of RIP-1, and found it was upregulated significantly in SW620 cells at $24 \mathrm{~h}$ with AA005 treatment (Figure 7A). We speculated that RIP-1 might participate in AA005-induced cell death. Inhibition of RIP-1 by Necrostatin-1 (Nec-1) in SW620 cells ameliorated cell death and AIF translocation after

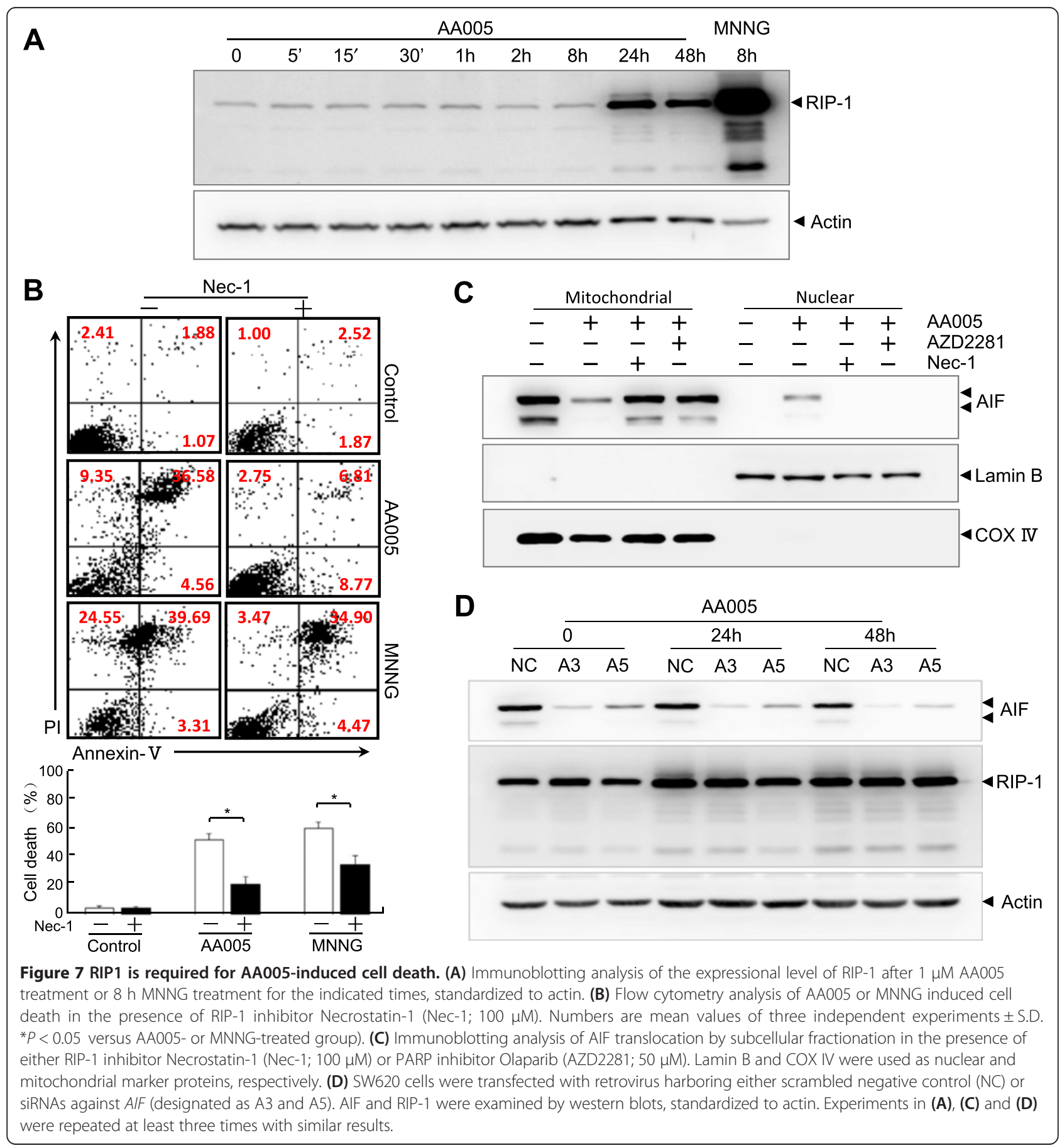


AA005 treatment (Figure 7B, C), whereas AIF knockdown failed to affect the increase in RIP-1 evoked by AA005 (Figure 7D). These observations imply that RIP1 activation is required for AIF translocation from the mitochondria to the nucleus and that RIP-1 is necessary for AIF-dependent cell death induced by AA005.

\section{Discussion}

Directed induction of cell death could provide therapeutic benefits for cancer treatment. Such treatments mainly target caspase pathways to induce apoptosis. However, caspase activation may be dispensable for some kinds of apoptosis, and increasing attention has been drawn to key molecules involved in non-apoptotic cell death or caspaseindependent apoptosis $[10,33]$. The mitochondrial protein AIF is a new therapeutic target involved in most of the caspase-independent apoptosis systems, including programmed necrosis [34].

In this work, we found that AA005 could induce cell death of SW620 cells and NB4 cells with evidence that implies a caspase-independent mechanism; we also found that AIF might be involved in this process. We also found that AA005-induced death of cancer cells provides a morphology similar to that of MNNG treated cells. Previous studies indicated that MNNG-mediated cell death was AIF-mediated and PARP-1-dependent, resulting in a caspase-independent type of apoptosis, called parthanatos $[20,25]$. Our findings indicate that AA005 targets AIF signaling by promoting its nuclear translocation. The fact that AA005-induced cell death is mostly blocked by AIF knockdown suggests that AIF is crucial to AA005induced cell death.

It has previously been reported that AAs were very potent inhibitors of the mitochondrial NADH-ubiquinone reductase (Complex I) and induced apoptosis by reducing intracellular cAMP and cGMP levels in human cancer [3,35]. Recently, Liu et al. revealed that AA005 co-localized with mitochondria in colon cancer cells. In their view, AA005 could activate AMP-activated protein kinase (AMPK) and inhibit the mTOR complex 1 (mTORC1) signal pathway, leading to growth inhibition and autophagy of colon cancer cells. However, AMPK inhibitors compound $\mathrm{C}$ and inosine can only partially attenuate AA005-caused proliferation suppression of colon cancer cells [36], indicating that other mechanisms affect the cancer suppression activity of AA005. In addition, the mechanism of Complex I inhibition by AA005 is unclear, although AIF is known to affect Complex I activity [24]. In fact, here we find that AA005 treatment decreased mitochondrial Complex I subunits, and significantly increased intracellular concentrations of ROS. AA005, as a novel ROS-inducing agent, may be an effective chemical probe to examine the mechanisms of tumor cells that are more sensitive and vulnerable to toxic oxidative stress [37]. Our research here shows RIP-1 activation is required for translocation of AIF from the mitochondria to the nucleus; and AIF is necessary for AA005-induced cell death, which is prevented by PARP inhibitors, RIP-1 inhibitors or knockdown of AIF, but is caspase independent. We speculate that AA005 may disrupt mitochondrial function by reducing mitochondrial Complex I expression, thus triggering ROS, RIP and AIFdependent pathway. Thus provides a new clue to the action of AA005.

As a core executor in caspase-independent cell death, AIF is intensively studied [11]. However, many studies' results are highly controversial. We suggest that AA005 is an effective chemical probe to examine the role of AIF. Furthermore, AA005 may be the basis of a novel treatment for cancers that are resistant to classical apoptotic reagents.

\section{Conclusions}

AA005 can induce an AIF-dependent but caspaseindependent cell death, which is mediated through ROS and RIP1. Our work shows new mechanisms for AA005induced cancer cell death and implies a novel cancer treatment via AIF dependent cell death.

\section{Abbreviations}

AIF: Apoptosis inducing factor; Complex I: NADH-ubiquinone reductase; MNNG: N-methyl-N'-nitro-N-nitrosoguanidine; NAC: N-acetyl-L-cysteine; Nec-1: Necrostatin-1.

\section{Competing interests}

The authors declare that they have no competing interests.

\section{Authors' contributions}

$\mathrm{BH}$ and LSW conceived and designed the experiments; $\mathrm{BH}$ and SMS performed the experiments; $\mathrm{BH}, \mathrm{ZJY}$ and LSW analyzed the data; CM, SMS, TDW, YY and

ZJY contributed reagents, materials and analysis tools; $\mathrm{BH}, \mathrm{SMS}$ and LSW wrote the paper. All authors read and approved the final manuscript.

\section{Acknowledgements}

This work is supported in part by grants from National Natural Science Foundation of China (81472758, 31170783, U1302225) and Ministry of Science and Technology of China (2013CB910903).

\section{Author details}

${ }^{1}$ Center for Molecular Medicine, Ruijin Hospital, Shanghai Jiao Tong University School of Medicine, Shanghai 200025, China. ${ }^{2}$ State Key Laboratory of Coordination Chemistry, Institute of Chemical Biology and Drug Innovation, School of Chemistry and Chemical Engineering, Nanjing University, Nanjing 210093, P. R. China. ${ }^{3}$ Shanghai Universities E-Institute for Chemical Biology, Shanghai 200025, China.

Received: 31 December 2014 Accepted: 24 February 2015 Published online: 18 March 2015

\section{References}

1. Alali FQ, Liu XX, McLaughlin JL. Annonaceous acetogenins: recent progress. J Nat Prod. 1999;62(3):504-40.

2. Chang FR, Wu YC. Novel cytotoxic annonaceous acetogenins from Annona muricata. J Nat Prod. 2001;64(7):925-31.

3. Degli Esposti M, Ghelli A, Ratta M, Cortes D, Estornell E. Natural substances (acetogenins) from the family Annonaceae are powerful inhibitors of mitochondrial NADH dehydrogenase (Complex I). Biochem J. 1994;301(Pt 1):161-7. 
4. Zeng BB, Wu Y, Jiang S, Yu Q, Yao ZJ, Liu ZH, et al. Studies on mimicry of naturally occurring annonaceous acetogenins: non-THF analogues leading to remarkable selective cytotoxicity against human tumor cells. Chemistry. 2003;9(1):282-90.

5. Jiang S, Li Y, Chen XG, Hu TS, Wu YL, Yao ZJ. Parallel fragment assembly strategy towards multiple-ether mimicry of anticancer annonaceous acetogenins. Angew Chem Int Ed Engl. 2004;43(3):329-34.

6. Yuan J, Lipinski M, Degterev A. Diversity in the mechanisms of neuronal cell death. Neuron. 2003:40(2):401-13.

7. Danial NN, Korsmeyer SJ. Cell death: critical control points. Cell. 2004;116(2):205-19.

8. Cregan SP, Dawson VL, Slack RS. Role of AIF in caspase-dependent and caspase-independent cell death. Oncogene. 2004;23(16):2785-96.

9. Hong SJ, Dawson TM, Dawson VL. Nuclear and mitochondrial conversations in cell death: PARP-1 and AIF signaling. Trends Pharmacol Sci. 2004;25(5):259-64.

10. Susin SA, Lorenzo HK, Zamzami N, Marzo I, Snow BE, Brothers GM, et al. Molecular characterization of mitochondrial apoptosis-inducing factor. Nature. 1999;397(6718):441-6.

11. Susin SA, Daugas E, Ravagnan L, Samejima K, Zamzami N, Loeffler M, et al. Two distinct pathways leading to nuclear apoptosis. J Exp Med. 2000;192(4):571-80.

12. Joza N, Susin SA, Daugas E, Stanford WL, Cho SK, Li CY, et al. Essential role of the mitochondrial apoptosis-inducing factor in programmed cell death. Nature. 2001;410(6828):549-54.

13. Daugas E, Susin SA, Zamzami N, Ferri KF, Irinopoulou T, Larochette N, et al. Mitochondrio-nuclear translocation of AIF in apoptosis and necrosis. FASEB J. 2000;14(5):729-39.

14. Wang X, Yang C, Chai J, Shi Y, Xue D. Mechanisms of AlF-mediated apoptotic DNA degradation in Caenorhabditis elegans. Science. 2002;298(5598):1587-92.

15. Parrish JZ, Xue D. Functional genomic analysis of apoptotic DNA degradation in C. elegans. Mol Cell. 2003;11(4):987-96.

16. Cande C, Vahsen N, Kouranti I, Schmitt E, Daugas E, Spahr C, et al. AlF and cyclophilin a cooperate in apoptosis-associated chromatinolysis. Oncogene. 2004;23(8):1514-21.

17. Zannini L, Buscemi G, Kim JE, Fontanella E, Delia D. DBC1 phosphorylation by ATM/ATR inhibits SIRT1 deacetylase in response to DNA damage. J Mol Cell Biol. 2012:4(5):294-303.

18. Duprez E, Ruchaud S, Houge G, Martin-Thouvenin V, Valensi F, Kastner P et al. A retinoid acid 'resistant' $t(15 ; 17)$ acute promyelocytic leukemia cell line: isolation, morphological, immunological, and molecular features. Leukemia. 1992;6(12):1281-7.

19. Liu HX, Shao F, Li GQ, Xun GL, Yao ZJ. Tuning the acyclic ether moiety of anticancer agent AA005 with conformationally constrained fragments. Chemistry. 2008;14(28):8632-9.

20. Yu SW, Wang H, Poitras MF, Coombs C, Bowers WJ, Federoff HJ, et al. Mediation of poly(ADP-ribose) polymerase-1-dependent cell death by apoptosis-inducing factor. Science. 2002;297(5579):259-63.

21. Song MG, Gao SM, Du KM, Xu M, Yu Y, Zhou YH, et al. Nanomolar concentration of NSC606985, a camptothecin analog, induces leukemic-cell apoptosis through protein kinase Cdelta-dependent mechanisms. Blood. 2005;105(9):3714-21.

22. Overbeeke R, Steffens-Nakken H, Vermes I, Reutelingsperger C, Haanen C. Early features of apoptosis detected by four different flow cytometry assays. Apoptosis Int J Program Cell Death. 1998;3(2):115-21.

23. Yang ZY, Qu Y, Zhang Q, Wei M, Liu CX, Chen XH, et al. Knockdown of metallopanstimulin-1 inhibits NF-kappaB signaling at different levels: the role of apoptosis induction of gastric cancer cells. Int J Cancer J Int Cancer. 2012;130(12):2761-70.

24. Shen SM, Yu Y, Wu ZX, Zheng Y, Chen GQ, Wang LS. Apoptosis-inducing factor is a target gene of C/EBPalpha and participates in adipocyte differentiation. FEBS Lett. 2011;585(14):2307-12

25. Kuzhandaivel A, Nistri A, Mladinic M. Kainate-mediated excitotoxicity induces neuronal death in the rat spinal cord in vitro via a PARP-1 dependent cell death pathway (Parthanatos). Cell Mol Neurobiol. 2010;30(7):1001-12.

26. Cardnell RJ, Feng Y, Diao L, Fan YH, Masrorpour F, Wang J, et al. Proteomic markers of DNA repair and PI3K pathway activation predict response to the PARP inhibitor BMN 673 in small cell lung cancer. Clin Cancer Res Off J Am Assoc Cancer Res. 2013;19(22):6322-8.
27. Modjtahedi N, Giordanetto F, Madeo F, Kroemer G. Apoptosis-inducing factor: vital and lethal. Trends Cell Biol. 2006;16(5):264-72.

28. Punj V, Chakrabarty AM. Redox proteins in mammalian cell death: an evolutionarily conserved function in mitochondria and prokaryotes. Cell Microbiol. 2003;5(4):225-31.

29. Huerta S, Heinzerling JH, Anguiano-Hernandez YM, Huerta-Yepez S, Lin J, Chen $\mathrm{D}$, et al. Modification of gene products involved in resistance to apoptosis in metastatic colon cancer cells: roles of Fas, Apaf-1, NFkappaB, IAPs, Smac/DIABLO, and AIF. J Surg Res. 2007;142(1):184-94.

30. Vazquez F, Lim JH, Chim H, Bhalla K, Girnun G, Pierce K, et al. PGC1alpha expression defines a subset of human melanoma tumors with increased mitochondrial capacity and resistance to oxidative stress. Cancer Cell. 2013;23(3):287-301.

31. Roca FJ, Ramakrishnan L. TNF dually mediates resistance and susceptibility to mycobacteria via mitochondrial reactive oxygen species. Cell. 2013;153(3):521-34.

32. Declercq W, Vanden Berghe T, Vandenabeele P. RIP kinases at the crossroads of cell death and survival. Cell. 2009;138(2):229-32.

33. Zanna C, Ghelli A, Porcelli AM, Martinuzzi A, Carelli V, Rugolo M. Caspaseindependent death of Leber's hereditary optic neuropathy cybrids is driven by energetic failure and mediated by AIF and Endonuclease G. Apoptosis Int J Program Cell Death. 2005;10(5):997-1007.

34. Kim R. Recent advances in understanding the cell death pathways activated by anticancer therapy. Cancer. 2005;103(8):1551-60.

35. Chiu HF, Chih TT, Hsian YM, Tseng CH, Wu MJ, Wu YC. Bullatacin, a potent antitumor Annonaceous acetogenin, induces apoptosis through a reduction of intracellular CAMP and CGMP levels in human hepatoma 2.2 .15 cells. Biochem Pharmacol. 2003;65(3):319-27.

36. Liu YQ, Cheng X, Guo LX, Mao C, Chen YJ, Liu HX, et al. Identification of an annonaceous acetogenin mimetic, AA005, as an AMPK activator and autophagy inducer in colon cancer cells. PLoS One. 2012;7(10):e47049.

37. Dittmer J, Leyh B. The impact of tumor stroma on drug response in breast cancer. Seminars in Cancer Biology. 2015;31C:3-15.

\section{Submit your next manuscript to BioMed Central and take full advantage of:}

- Convenient online submission

- Thorough peer review

- No space constraints or color figure charges

- Immediate publication on acceptance

- Inclusion in PubMed, CAS, Scopus and Google Scholar

- Research which is freely available for redistribution 